MING ZHANG, Ph.D. ${ }^{1}$

(Corresponding author)

E-mail: zhangm@nuaa.edu.cn

SHUO WANG, Master ${ }^{1}$

E-mail:w0913s@163.com

HUI YU, Master ${ }^{1}$

E-mail: yuhui19920118@163.com

${ }^{1}$ College of Civil Aviation, Nanjing University of Aeronautics

and Astronautics, Nanjing, 210016, China
Transport in Emergency Situations Original Scientific Paper Submitted: Sep. 9, 2015

Accepted: Apr. 12, 2016

\title{
A METHOD OF RESCUE FLIGHT PATH PLAN CORRECTION BASED ON THE FUSION OF PREDICTED LOW-ALTITUDE WIND DATA
}

\begin{abstract}
This study proposes a low-altitude wind prediction model for correcting the flight path plans of low-altitude aircraft. To solve large errors in numerical weather prediction (NWP) data and the inapplicability of high-altitude meteorological data to low altitude conditions, the model fuses the low-altitude lattice prediction data and the observation data of a specified ground international exchange station through the unscented Kalman filter (UKF)-based NWP interpretation technology to acquire the predicted low-altitude wind data. Subsequently, the model corrects the arrival times at the route points by combining the performance parameters of the aircraft according to the principle of velocity vector composition. Simulation experiment shows that the RMSEs of wind speed and direction acquired with the UKF prediction method are reduced by $12.88 \%$ and $17.50 \%$, respective ly, compared with the values obtained with the traditional Kalman filter prediction method. The proposed prediction model thus improves the accuracy of flight path planning in terms of time and space.
\end{abstract}

\section{KEY WORDS}

low-altitude rescue; flight path correction; meteorological prediction model; unscented Kalman filter;

\section{INTRODUCTION}

With its advantages of wide rescue range, fast response, and small restriction by geographical factors, air emergency rescue plays an irreplaceable role in preventing and reducing disasters in many countries. The aircraft used for rescue are mostly small and medium-sized helicopters or generic fixed-wing aircraft. Given the low flying altitude of such aircraft, ground communication, navigation, and surveillance systems have difficulty in effectively covering their flying airspace; hence, pilots are mainly responsible for flight safety. Several aircraft conduct rescue missions at the same time when major accidents or disasters occur. However, the limited low-altitude airspace is relatively narrow, thus increasing the possibility of aircraft conflict. In order to keep a safe separation of other aircraft and reduce the probability of the conflict, the focus is on making a precise flight path planning of every aircraft based on the rescue task. Thus, accurate flight path planning is significant in the safe operation of rescue aircraft.

The meteorological conditions in the flying airspace of an aircraft are an important factor that causes a deviation between the actual operating path and the planned operating path during an actual flight. Therefore, considering the influence of meteorological conditions on flights is an effective measure to improve the authenticity of path planning [1]; the key is accurately predicting low-altitude wind, as well as analyzing aircraft motion in the wind field. At present, the methods for predicting low-altitude wind can be divided into three categories. The first category involves the direct use of the numerical weather prediction (NWP) products issued by the World Aero Forecast System, such as the lattice predicted data stored in GRIB and NetCDF formats. The second category involves the use of various prediction methods on the basis of historical meteorological data; examples of such methods include the continuous model, autoregressive moving average model [2], Kalman filtering method [3], and mixed prediction method $[4,5]$. The third category involves the use of NWP interpretation technology, which fuses local meteorological observation data and NWP data. For example, the fusion of measured AMDAR data [6] and GRIB data can improve the temporal-spatial resolution and accuracy of route meteorological forecast. However, these methods also have their disadvantages. NWP data feature large time intervals and system errors. The prediction based on historical meteorological data is mostly used in wind speed prediction at points where the wind field is located. Thus, such prediction method cannot satisfy the requirement of acquiring the meteorological data of several route points in flight path planning. In the 
application of NWP interpretation technology, most small aircraft flying in low altitude fail to acquire real-time meteorological data such as AMDAR because of limitations in airborne equipment; hence, such data sources do not apply to low-altitude conditions. Three methods are used to analyze the influence of wind on the operation of an aircraft. The first method is to establish a motion model on the basis of aircraft dynamics [7] and with consideration of the effect of wind. This method requires a specific motion model according to the performance parameters of different aircraft; hence, it has poor universality. The second method is the trajectory prediction algorithm based on data mining [8], which mines the historical flight characteristics of aircraft among a large amount of historical data [9]. Given its large data requirement, this method has low processing efficiency. The third method is to process the wind field where the aircraft is as an uncertain stochastic system $[10,11]$ and to fit the trajectories of the aircraft with Kalman filtering [12] or Markov chain [13]; however, this method has low accuracy.

The method proposed in the present study acquires the predicted values at any point on the flight route with a spatial interpolation model to overcome the problem in which NWP data are located in a particular lattice. To solve the large errors of NWP data and the inapplicability of high-altitude meteorological data to low-altitude conditions, the proposed method fuses the low-altitude lattice prediction data and observation data of a specified ground international exchange station through the unscented Kalman filter (UKF)-based NWP interpretation technology to acquire the predicted low-altitude wind data. Finally, our method combines the wind speed and direction at the route points, as well as the true airspeed of the aircraft, to calculate the corrected groundspeed of the aircraft through vector composition. In this way, the proposed method corrects the arrival times at the route points and improves the accuracy of flight path planning in terms of time and space.

\section{PREDICTED DATA ACQUISITION BASED ON SPATIAL INTERPOLATION MODEL}

This study uses the predicted data in NetCDF format provided by the European Centre for Medium-Range Weather Forecasts. The predicted data contain five pressure contour surfaces, namely, 1,000 mbar, 975 mbar, 950 mbar, 925 mbar and 900 mbar. In standard atmospheric conditions, the corresponding altitudes can be calculated as $110.82 \mathrm{~m}, 323.19$ $\mathrm{m}, 540.03 \mathrm{~m}, 761.53 \mathrm{~m}$, and $987.94 \mathrm{~m}$ according to the relationship between atmospheric pressure and altitude, that is,

$$
P=P_{0}\left(1-\frac{H}{44,330}\right)^{5.5288}
$$

where $H$ refers to the height above sea level (unit: $m$ ), $P$ refers to the atmospheric pressure at $H$ (unit: mbar), and $P_{0}$ refers to the standard sea-level pressure of 1,013.25 mbar.

The region where a planned flight path is and the coordinates of the exchange station in this region are determined according to the flight plan. Given the randomness of the location distribution of the exchange station, its 3D coordinates (latitude, longitude, and height) will not coincide with the lattice coordinates of the predicted data in general. Thus, the predicated data need to be interpolated into the coordinates where the data recorded by the exchange station are located. Thus, this study proposes a spatial interpolation model.

Eight neighbouring lattice data can be determined according to the 3D coordinates of the station when an exchange station is selected. Their positions form a hexahedron in space; the exchange station is located at a certain point in the hexahedron, as shown in Figure 1. Because the earth is an approximate sphere, this hexahedron is not a cuboid.

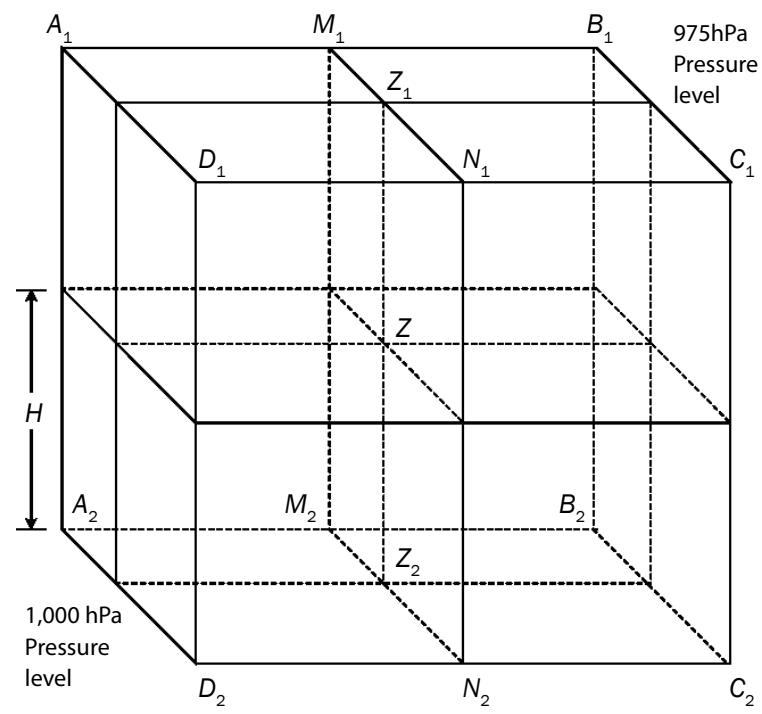

Figure 1 - Diagram of the Spatial Interpolation Model

Given that the coordinates of $Z$ (position of the exchange station) are known, the coordinates of the hexahedral vertices and the $u$ and $v$ values at the vertices can be obtained from the NetCDF data, $u$ and $v$ mean the wind speed along the latitude and longitude respectively. The $u$ and $v$ values of $Z$ can then be obtained after several two-point linear interpolation calculations. For example, when solving the $v$ value of $Z$, the $v$ value at $M_{1}$ must be calculated as

$$
v\left(M_{1}\right)=v\left(B_{1}\right)+\left[v\left(A_{1}\right)-v\left(B_{1}\right)\right] \cdot \frac{\left(x_{M_{1}}-X_{B_{1}}\right)}{\left(x_{A_{1}}-X_{B_{1}}\right)}
$$

In the formula, $v\left(A_{1}\right)$ and $v\left(B_{1}\right)$ are the wind components at $A_{1}$ and $B_{1}$ along the longitude direction, 
respectively; and $x_{M_{1}}, x_{A_{1}}$, and $x_{B_{1}}$ are the latitudes of $M_{1}, A_{1}$, and $B_{1}$, respectively. The $v$ values of $N_{1}, M_{2}$, and $N_{2}$ can be also calculated with the interpolation method. The latitude and longitude coordinates of $Z_{1}$ and $Z_{2}$ are the same as those of $Z$. These two points are located on the upper and lower isobaric surfaces near $Z$, respectively. Thus, $v\left(Z_{1}\right)$ and $v\left(Z_{2}\right)$ can be obtained according to the interpolation calculation of $M_{1}$ and $N_{1}$ and $M_{2}$ and $N_{2}$, respectively. By interpolating $Z_{1}$ and $Z_{2}$, one can obtain the wind component $v$ of $Z$. Similarly, the wind component $u$ of $Z$ can be solved. Consequently, the wind speed and direction can be solved.

\section{METEOROLOGICAL DATA FUSION BASED ON UKF}

Given that low-altitude air movement is seriously affected by orographic disturbance and surface friction, which lead to air current chaos, low-altitude wind and the wind in the free atmosphere in high altitude show different characteristics. Low-altitude wind is characterized by strong stochastic volatility, and its observation values have obvious non-linear characteristics. UKF has a strong ability to deal with stochastic volatility; hence, it is applicable to the estimation of non-linear systems formed by wind speed and direction. Specifically, UKF is an algorithm that combines unscented transformation and Kalman filtering [14] and solves the predicted values of follow-up times with sample points. UKF uses unscented transformation to approximate the probability density distribution of a non-linear function. Unscented transformation is a method of calculating the statistical properties of random variables. This method constructs a $\sigma$ set according to the mean and variance of given amounts and performs non-linear transformation and weighted calculation on the set to obtain the updated filtering value, that is, the predicted value of the system at the next moment, through a non-linear state equation.

Assuming that $x$ is the state vector of $L$ dimensions with a mean of $\bar{x}$ and a variance of $P_{X}$ and according to the statistics $\bar{x}$ and $P_{X}$ of $X, 2 L+1$ weighted sample points $S_{i}\left\{W_{i}, X_{i}\right\}$ are selected to approximate the distribution of the state vector $x$, in which $W_{i}$ is the weight of $X_{i}$ and $X_{i}$ and is called the $\sigma$ point. The $\sigma$ set is obtained as follows:

$$
\chi_{i}=\left\{\begin{array}{l}
\bar{x}, i=0 \\
\bar{x}+\left(\sqrt{(L+\lambda) P_{x}}\right)_{i}, i=1, \ldots, L \\
\bar{x}-\left(\sqrt{(L+\lambda) P_{x}}\right)_{i-L}, i=L+1, \ldots, 2 L
\end{array}\right.
$$

where $\lambda$ is the scale parameter. Adjusting $\lambda$ can improve approximation accuracy. This group of sample points $X_{i}$ can approximately represent the Gaussian distribution of the state vector $x$.
After the $f(\cdot)$ non-linear transformation of the constructed point set $\left\{X_{i}\right\}$, the transformed $\sigma$ set $Y_{i}=f\left(X_{i}\right)$, $i=0,1, \ldots, 2 L$ can be obtained. The transformed $\sigma$ set $\left\{Y_{i}\right\}$ an approximately represent the distribution of $y=f(x)$.

$\bar{y} \approx \sum_{i=0}^{2 L} W_{i}^{(m)} Y_{i}$

$P_{y} \approx \sum_{i=0}^{2 L} W_{i}^{(c)}\left(Y_{i}-\bar{y}\right)\left(Y_{i}-\bar{y}\right)^{T}$

where $W_{i}^{(m)}$ and $W_{i}^{(c)}$ are the weights for calculating the mean and variance of $y$, respectively. The calculation formula is given by

$$
\begin{aligned}
& W_{0}^{(m)}=\frac{\lambda}{L+\lambda} \\
& W_{0}^{(c)}=\frac{\lambda}{L+\lambda}+\left(1-\alpha^{2}+\beta\right) \\
& W_{i}^{(m)}=W_{i}^{(c)}=\frac{1}{2(L+\lambda)}, i=1, \ldots, 2 L
\end{aligned}
$$

where $\lambda=\alpha^{2}(L+K)-L$.

Three parameters, namely $\alpha, \beta$, and $\kappa$, must be determined in the mean and variance weighting. Their significance and value ranges are as follows. The value of $\alpha$ determines the distribution of $\sigma$ around $\bar{x}$, which is usually set to a small positive number $\left(1 e^{-3} \leq \alpha<1\right)$, here, $\alpha=0.001$. $\beta$ is the state distribution parameter, with $\beta=2$ being the optimal value for a Gaussian distribution. If the state variable is a single one, $\beta=0$ is the optimal value. $k$ is the second scale parameter, which is usually set to 0 or $3-n, n$ is the dimension of state variable. The proper adjustment of $\alpha$ and $k$ can improve the accuracy of the estimated mean; such adjustment can improve the precision of variance.

The values of wind speed and direction with respect to the time series can be regarded as the discrete non-linear system as follows:

$$
\begin{aligned}
& x_{k+1}=f\left(x_{k}\right)+w_{k} \\
& y_{k}=h\left(x_{k}\right)+v_{k}
\end{aligned}
$$

Assuming that the process noise $w_{k}$ and the measurement noise $v_{k}$ are the white Gaussian noises with a mean of 0 and covariances of $Q_{k}=0.01$ and $R_{k}=0.25$, respectively, and are unrelated to each other, the UKF algorithm is represented as follows:

1) Initialization condition:

$$
\begin{aligned}
& \widehat{x}_{0}=E\left[x_{0}\right] \\
& P_{0}=E\left[\left(x_{0}-\widehat{x}_{0}\right)\left(x_{0}-\widehat{x}_{0}\right)^{T}\right] \\
& 2) \text { For } k \in\{1, \ldots, \infty\}, \sigma \text { is calculated to obtain } \\
& x_{k-1}^{\alpha}=\left[\widehat{x}_{k-1}^{\alpha} \widehat{x}_{k-1}^{\alpha} \pm \sqrt{(L+\lambda) P_{k-1}^{\alpha}}\right]
\end{aligned}
$$

3) Time propagation equation:

$$
\chi_{k \mid k-1}^{x}=F\left[\chi_{k-1}^{\chi}, \chi_{k-1}^{v}\right]
$$




$$
\begin{aligned}
& \widehat{\chi}_{k}^{-}=\sum_{i=0}^{2 L} W_{i}^{(m)} \chi_{i, k \mid k-1}^{\chi} \\
& P_{k}^{-}=\sum_{i=0}^{2 L} W_{i}^{(c)}\left[\chi_{i, k \mid k-1}^{\chi}-\widehat{x}_{k}^{-}\right]\left[\chi_{i, k \mid k-1}^{\chi}-\widehat{x}_{k}^{-}\right]^{T} \\
& Y_{k \mid k-1}=H\left[\chi_{k \mid k-1}^{\chi}, \chi_{k-1}^{n}\right] \\
& \widehat{y}_{k}^{-}=\sum_{i=0}^{2 L} W_{i}^{(m)} Y_{i, k \mid k-1}
\end{aligned}
$$

4) Measurement updating equation:

$$
\begin{aligned}
& P_{\bar{y}_{k} \bar{y}_{k}}=\sum_{i=0}^{2 L} W_{i}^{(c)}\left[Y_{i, k \mid k-1}-\widehat{y}_{k}^{-}\right]\left[Y_{i, k \mid k-1}-\widehat{y}_{k}^{-}\right]^{T} \\
& P_{x_{k} y_{k}}=\sum_{i=0}^{2 L} W_{i}^{(c)}\left[\chi_{i, k \mid k-1}-\widehat{x}_{k}^{-}\right]\left[Y_{i, k \mid k-1}-\widehat{y}_{k}^{-}\right]^{T} \\
& K=P_{x_{k} y_{k}} P_{\bar{x}_{k} \bar{y}_{k}}^{-1} \\
& \widehat{x}_{k}=\widehat{x}_{k}^{-}+K\left(y_{k}-\widehat{y}_{k}^{-}\right) \\
& P_{k}=P_{k}^{-}-K P_{\bar{y}_{k} \bar{y}_{k}} K^{T}
\end{aligned}
$$

In Equations 11 to 23, the subscript $k$ in the variables refers to the discrete time point in the data sequence of wind speed or direction, and the serial number $i$ refers to the $i^{\text {th }}$ component of the vector. $\widehat{x}_{k}$ is the estimate of the system state at $k$ by the UKF algorithm, and $P_{k}$ is the estimate of the system state variance at $k$. The predicted values obtained with the UKF algorithm are different from the NWP data. Such difference is known as the system error of numerical prediction. After correcting the error according to the original predicted values, highly accurate wind speed and direction values can be obtained.

\section{FLIGHT PATH CORRECTION BASED ON VELOCITY VECTOR COMPOSITION}

After determining the flight path and wind velocity, the velocity vector composition algorithm can be used to analyze the effect of wind on the flight and solve the airspeed of the aircraft and the resultant velocity of wind speed, that is, the groundspeed. The flight times of different legs and the arrival times at different route points can then be determined by the groundspeed.

\section{1) Effect of wind on groundspeed}

As shown in Figure 2, $A B$ is the initially planned flight path. If the aircraft maintains the heading angle equal to the course angle when encountering crosswind $V_{\text {wind }}$, it will deviate from the planned flight path $A B$ under the influence of crosswind. To make the aircraft fly along the planned path, that is, making the path angle equal to the course angle, the aircraft should veer windward so as to balance the drift caused by the crosswind.

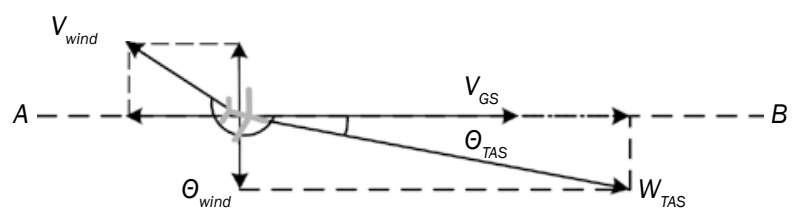

Figure 2 - Groundspeed composition diagram

Groundspeed is solved according to the airspeed of the aircraft, wind speed, and wind direction, that is,

$V_{\mathrm{GS}}=V_{T A S} \cdot \cos \theta_{\text {TAS }}+V_{\text {wind }} \cdot \cos \theta_{\text {wind }}$

where $V_{G S}$ refers to the groundspeed, $V_{T A S}$ refers to the airspeed, $V_{\text {wind }}$ refers to the wind speed, $\theta_{\text {wind }}$ refers to the angle between the flight course and the flight path, and $\theta_{\text {TAS }}$ refers to the angle between the wind direction and the flight path. In addition, wind has no influence on the climbing and descending rates in the process of aircraft ascent and descent, but it changes the speed of the aircraft in the horizontal direction. Thus, the time for the aircraft to climb or descend to a specified height is not affected; however, the arrival position may be biased. $A-B-C-D, A-B_{1}-C_{1}-D$, and $A-B_{2}-$ $C_{2}-D$ in Figure 3 are the flight profiles in no-wind conditions, adverse wind conditions, and favourable wind conditions, respectively.

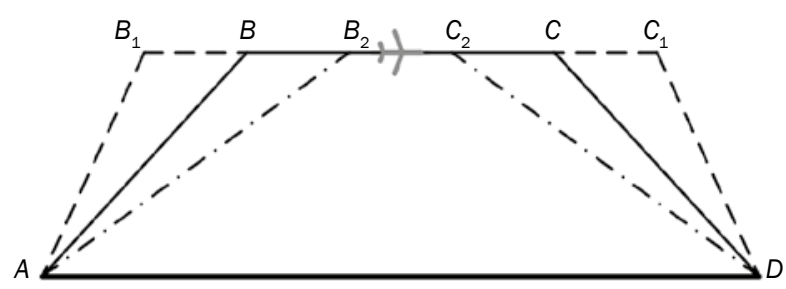

Figure 3 - Flight profiles under the influence of wind

2) Calculation of arrival times at the route points

It is assumed that the coordinates of route points $i$ and $i+1$ are known and that the aircraft passes $i$ at $T_{i}$. According to the method mentioned previously, the corrected groundspeeds of $i$ and $i+1$ are solved and written as $V_{G S}$ and $V_{G S}^{\prime}$, respectively. Then, the average groundspeed in this flight leg can be calculated by the corrected groundspeeds of $i$ and $i+1$ :

$\bar{V}_{G S}=\frac{\left(V_{G S}+V_{G S}^{\prime}\right)}{2}$

The flight leg distance $D$ can be solved by the coordinates of $i$ and $i+1$. Then, the time $\Delta T$ for flying across the leg in the presence of wind is determined by

$\Delta T=\frac{D}{\bar{V}_{\mathrm{GS}}}$

The arrival time at the route point $i+1$ is $T_{i}+\Delta T$. After correcting the arrival times at the route points on the original planned path successively, the corrected 
planned path under the influence of low-altitude wind is obtained.

\section{EXAMPLE ANALYSIS}

A Z-9 that undertakes personnel transfer missions is taken as an example in this study. In the whole flight process, the helicopter is assumed to climb to $500 \mathrm{~m}$ high above sea level and then levels off. During the level flight, the aircraft flies with a constant cruising speed in a straight line. In the climbing and landing stages, the aircraft flies with constant acceleration at an average speed that is half of the cruising speed in a straight line; the average rates for both the climbing and descending stages are half of the standard rate of climb, equals $2 \mathrm{~m} / \mathrm{s}$.

On the basis of the temporal-spatial parameters of the initially planned flight path, we select the predicted lattice data of three isobaric surfaces with pressure altitudes of 1,000 mbar, $975 \mathrm{mbar}$, and $950 \mathrm{mbar}$ and a coverage range of $118.625^{\circ} \mathrm{E}$ to $119.125^{\circ} \mathrm{E}$ and $31.5^{\circ} \mathrm{N}$ to $32^{\circ} \mathrm{N}$ within $48 \mathrm{~h}$ before the flight. The meteorological data of the international exchange station (No. 58,238) in this area on the same day and its spatial coordinates $\left(118.862^{\circ} \mathrm{E}, 31.742^{\circ} \mathrm{N}\right.$ and $\left.14.9 \mathrm{~m}\right)$ are acquired. The wind velocity of the predicted data at the coordinates of the exchange station is solved by the hexahedron interpolation model, as shown in Table 1.

Table 1 - Predicted values of wind velocity at the exchange station

\begin{tabular}{||c|c|c||}
\hline Time Series & Wind Speed $(\mathrm{m} / \mathrm{s})$ & Wind Direction $\left({ }^{\circ}\right)$ \\
\hline \hline 1 & 9.14 & 178.78 \\
\hline 2 & 6.82 & 178.78 \\
\hline 3 & 10.56 & 178.85 \\
\hline 4 & 10.76 & 178.96 \\
\hline 5 & 11.38 & 179.07 \\
\hline 6 & 9.63 & 178.86 \\
\hline 7 & 12.80 & 178.85 \\
\hline 8 & 10.78 & 178.86 \\
\hline
\end{tabular}

The numerical predicted data are corrected with the UKF method on the basis of observation data from the exchange station within $48 \mathrm{~h}$ before the flight to obtain the values of wind speed and direction at the corresponding times. The predicted result shows an obvious improvement with respect to the result obtained with Kalman filtering, as shown in Figures 4 a), b), c), and d). The system error of the NWP can be obtained by comparing the predicted values with the observation values. The wind speed correction is $\Delta V=$ $-1.74 \mathrm{~m} / \mathrm{s}$, and the forecast wind direction correction is $\Delta \varphi=-63.30^{\circ}$.

The predicted results of the Kalman filtering and UKF are evaluated by three indices, namely, average error $e_{M}$, average absolute error $e_{M A}$, and root-meansquare error $e_{\text {RMSE. }}$. Their calculation Formulas are shown in 27,28 , and 29 . The prediction errors of wind speed and direction obtained with the two methods are listed in Tables 2 and 3, respectively.

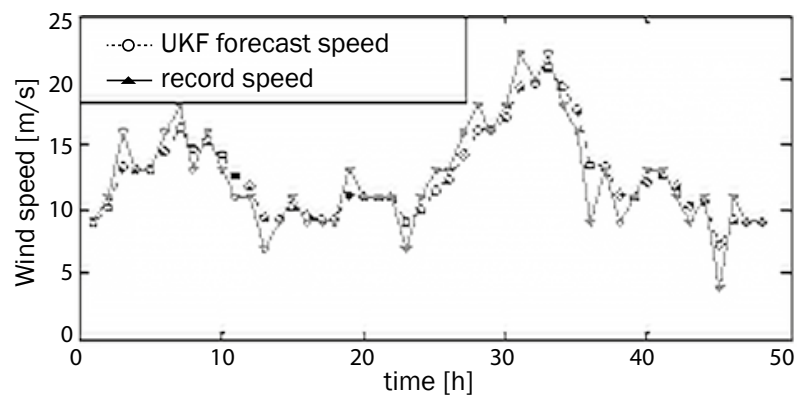

a)

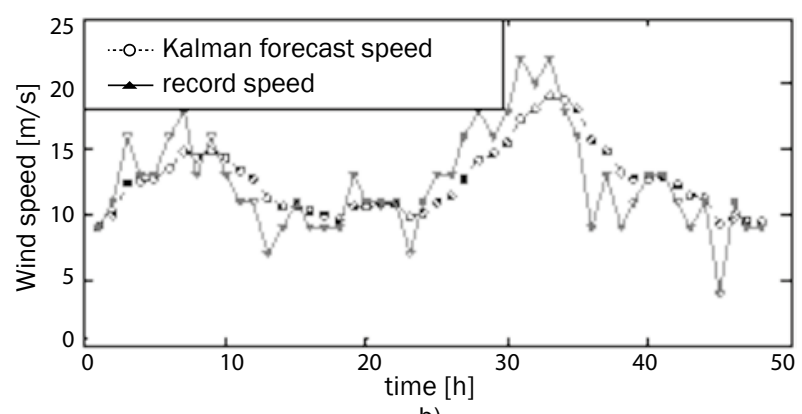

b)

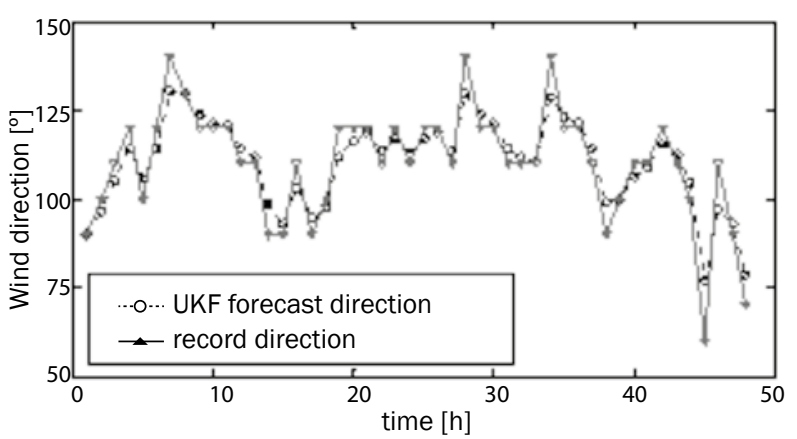

c)

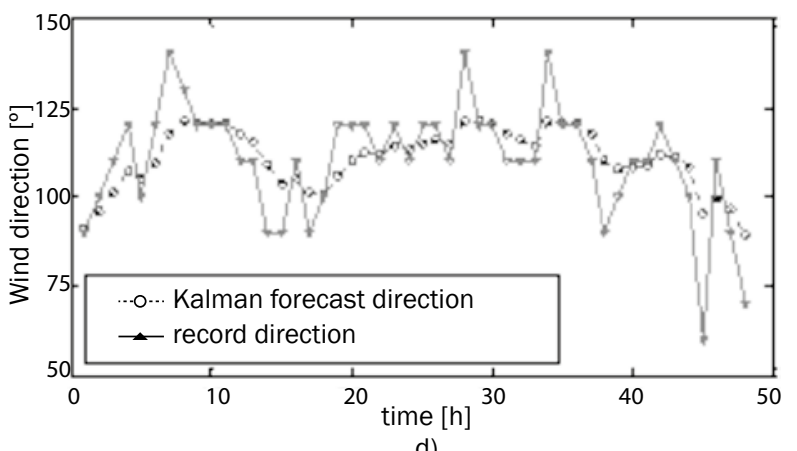

d)

Figure 4 - Prediction curves of wind speed and direction by UKF and Kalman Filtering

$e_{M}=\frac{1}{k} \sum_{i=1}^{k}\left(f_{i}-o_{i}\right)$ 
$e_{M A}=\frac{1}{k} \sum_{i=1}^{k}\left|f_{i}-o_{i}\right|$

$e_{\text {RMSE }}=\sqrt{\frac{1}{k} \sum_{i=1}^{k}\left(f_{i}-o_{i}\right)^{2}}$

where $f_{i}$ and $o_{i}(i=1, \ldots, k)$ are estimates and observations. Figures 5 a) and 5 b) show the predicted RMSE curves of wind speed and wind direction obtained with Kalman filtering and UKF, respectively. The predicted RMSEs of wind speed and direction obtained with UKF show a reduction of $12.88 \%$ and $17.50 \%$, respectively, in comparison with the prediction results of Kalman filtering. The prediction results are significantly improved.

Table 2 - Wind speed forecast error

\begin{tabular}{||c|c|c||}
\hline Indices & Kalman & UKF \\
\hline \hline$e_{M}(\mathrm{~m} / \mathrm{s})$ & -0.08 & -0.04 \\
\hline$e_{M A}(\mathrm{~m} / \mathrm{s})$ & 1.84 & 0.84 \\
\hline$e_{R M S E}(\%)$ & 14.96 & 2.08 \\
\hline
\end{tabular}

Table 3 - Wind direction forecast error

\begin{tabular}{||c|c|c||}
\hline Indices & Kalman & UKF \\
\hline \hline$e_{M}\left({ }^{\circ}\right)$ & -0.24 & -0.11 \\
\hline$e_{M A}\left({ }^{\circ}\right)$ & 5.68 & 3.12 \\
\hline$e_{\text {RMSE }}(\%)$ & 29.47 & 11.97 \\
\hline
\end{tabular}

The interpolation method is used to calculate Z-9 after the route forecast wind velocity. Consequently, the system error is eliminated and can be concluded as the route point correction wind velocity. The route points of the helicopter used in this study are presented in Table 4, which also shows the route correction of wind speed, wind direction, and speed.

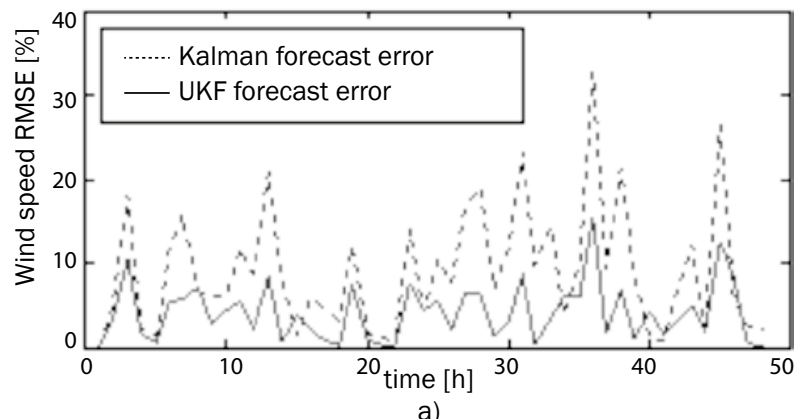

a)

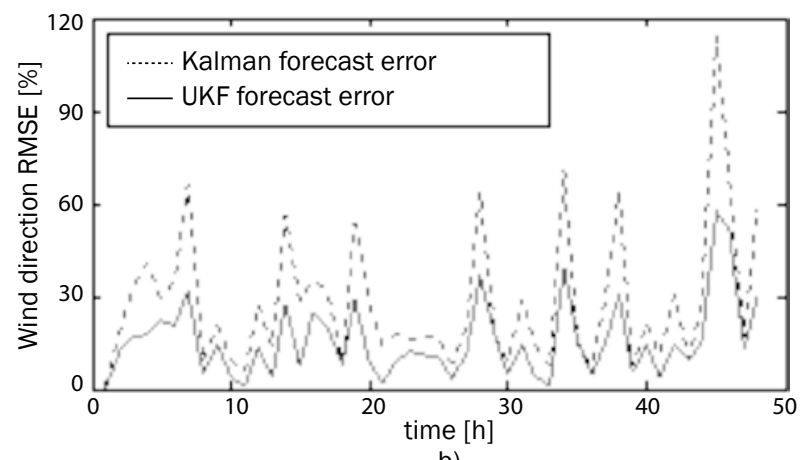

b)

Figure 5 - Forecast RMSE curves by UKF and Kalman Filtering

Table 4 - Parameters of the route points passed by Z-9

\begin{tabular}{||c|c|c||c||}
\hline Waypoint & $\begin{array}{c}\text { Wind Speed } \\
(\mathrm{m} / \mathrm{s})\end{array}$ & $\begin{array}{c}\text { Wind Direc- } \\
\text { tion }\left({ }^{\circ}\right)\end{array}$ & $\begin{array}{c}\text { Groundspeed } \\
(\mathrm{m} / \mathrm{s})\end{array}$ \\
\hline \hline 1 & 9.10 & 229.30 & 0 \\
\hline 2 & 8.07 & 251.96 & 62.51 \\
\hline 3 & 8.44 & 254.00 & 62.10 \\
\hline 4 & 9.25 & 234.71 & 0 \\
\hline
\end{tabular}

The flight times in different legs can be obtained by substituting the groundspeeds of the aircraft at different route points. The arrival times at the route points

Table 5 - Comparison between the planned and corrected flight paths

\begin{tabular}{|c|c|c|c|}
\hline \multicolumn{2}{|c|}{ Parameter } & Planned Flight Path & Corrected Flight Path \\
\hline \multirow{3}{*}{ Take-off Position } & Longitude & $118.625^{\circ} \mathrm{E}$ & $118.625^{\circ} \mathrm{E}$ \\
\hline & Latitude & $31.775^{\circ} \mathrm{N}$ & $31.775^{\circ} \mathrm{N}$ \\
\hline & Altitude & $11 \mathrm{~m}$ & $11 \mathrm{~m}$ \\
\hline \multicolumn{2}{|c|}{ Take-off Time } & 00:00:00 & 00:00:00 \\
\hline \multirow{3}{*}{$\begin{array}{l}\text { Level Flight } \\
\text { Beginning Position }\end{array}$} & Longitude & $118.714^{\circ} \mathrm{E}$ & $118.695^{\circ} \mathrm{E}$ \\
\hline & Latitude & $31.769^{\circ} \mathrm{N}$ & $31.770^{\circ} \mathrm{N}$ \\
\hline & Altitude & $500 \mathrm{~m}$ & $500 \mathrm{~m}$ \\
\hline \multicolumn{2}{|c|}{ Level Flight Beginning Time } & 00:04:05 & 00:04:16 \\
\hline \multirow{3}{*}{$\begin{array}{c}\text { Level Flight } \\
\text { Ending Position }\end{array}$} & Longitude & $118.912^{\circ} \mathrm{E}$ & $118.931^{\circ} \mathrm{E}$ \\
\hline & Latitude & $31.756^{\circ} \mathrm{N}$ & $31.755^{\circ} \mathrm{N}$ \\
\hline & Altitude & $500 \mathrm{~m}$ & $500 \mathrm{~m}$ \\
\hline \multicolumn{2}{|c|}{ Level Flight Ending Time } & 00:08:35 & 00:08:19 \\
\hline \multirow{3}{*}{ Descent Position } & Longitude & $119^{\circ} \mathrm{E}$ & $119^{\circ} \mathrm{E}$ \\
\hline & Latitude & $31.75^{\circ} \mathrm{N}$ & $31.75^{\circ} \mathrm{N}$ \\
\hline & Altitude & $19 \mathrm{~m}$ & $19 \mathrm{~m}$ \\
\hline \multicolumn{2}{|c|}{ Descent Time } & $00: 12: 36$ & $00: 12: 20$ \\
\hline
\end{tabular}


under the influence of wind can then be obtained. The location of the route points and time information of the initially planned flight path are updated. As shown in Table 5, after comparing the initially planned flight path and the corrected one under the influence of favourable wind, the position of the aircraft arriving at the level flight height after climbing moves backward, thus ending the level flight and beginning the forward landing movement. In this instance, both the cruising distance and time are reduced.

\section{CONCLUSION}

Air rescue requires quick reaction, efficient performance, scientific implementation, and safe operation. The planned flight path of an aircraft should keep a safe separation of other aircraft in a low-altitude environment. However, the low-altitude wind is an important factor that causes a deviation between the actual operating path and the planned operating path during an actual flight. In order to correct the deviation in a low-altitude environment, this study established a weather prediction correction model. The vector wind data of different route points are acquired through the interpolation model, which fuses the recorded data and the predicted data through UKF-based NWP interpretation technology. The proposed method calculates the groundspeed of the aircraft with vector composition and corrects the arrival times at the route points. The test consequence shows that the proposed model improves the accuracy of flight path planning in terms of time and space compared with the models presented in previous research. Given the instability and difficult prediction of low-altitude wind, further research will focus on the fusion of multi-source, low-altitude meteorological data and the correction of flight path in a special low-altitude environment, such as wind shear and mountain flight, to improve the accuracy of flight path prediction under complex low-altitude wind.

\section{ACKNOWLEDGMENTS}

This study was supported by the National Science Foundation of China (No. U1233101, and No. 71271113) and the Fundamental Research Funds for the Central Universities (No. NS2016062).

$$
\begin{aligned}
& \text { 张明, 王硕, 喻慧 } \\
& \text { 基于气象预测模型的低空规划航迹修正方法 }
\end{aligned}
$$

\section{摘要}

本文提出了采用低空风预测模型来修正低空航空器 飞行路径方法。考虑采用数值天气预测数据存在较 大误差, 且高空气象数据不适用于低空运行环境, 模型将低空网格预测数据和飞行区域内的国际交换 站数据, 通过应用基于无迹卡尔曼滤波（UKF）的 数值气象预报释用技术，将观测点的风速、风向记 录数据与预报值进行融合, 校正预报数据的系统
误差, 得出修正预测值。最后, 结合航空器的爬升 率、巡航速度等性能参数与所经航路点的风速、风 向信息, 依据速度矢量合成原理, 修正各航路点的 过点时刻。仿真实验表明，与传统的卡尔曼滤波预 测方法相比, 由UKF方法预测得到的风速、风向RMSE 分别减少了 $12.88 \%$ 与 $17.50 \%$, 对初始规划航迹的修 正更为精确。

\section{关键词 \\ 低空救援; 航迹修正; 气象预测模型; 无迹卡尔曼 滤波}

\section{REFERENCES}

[1] Korn B, Helmke $H$, Kuenz A. 4D trajectory management in the extended TMA: coupling AMAN and 4D FMS for optimized approach trajectories. 25th ICAS; Hamburg, Germany; 2006.

[2] Torres JL, Garcia A, De Blas M, et al. Forecast of hourly average wind speed with ARMA models in Navarre (Spain). Solar Energy. 2005;79(1):65-77.

[3] Louka P, Galanis G, Siebert N, et al. Improvements in wind speed forecasts for wind power prediction purposes using Kalman filtering. Journal of Wind Engineering and Industrial Aerodynamics. 2008;96(12): 2348-2362.

[4] Chen K, Yu J. Short-term wind speed prediction using an unscented Kalman filter based state-space support vector regression approach. Applied Energy. 2014;113:690-705.

[5] Tagliaferri F, Viola IM, Flay RGJ. Wind direction forecasting with artificial neural networks and support vector machines. Ocean Engineering. 2015;97:65-73.

[6] Frehlich R, Sharman R. Climatology of velocity and temperature turbulence statistics determined from rawinsonde and ACARS/AMDAR data. Journal of Applied Meteorology and Climatology. 2010;49(6): 1149-1169.

[7] Fukuda Y, Shirakawa M, Senoguchi A. Development of Trajectory Prediction Model. Tokyo, Japan: ENRI International Workshop on ATM/CNS (EIWAC); 2010.

[8] Hurter C, Alligier R, Gianazza D, et al. Wind parameters extraction from aircraft trajectories. Computers, Environment and Urban Systems, 2014;47:28-43.

[9] Gariel M, Srivastava AN, Feron E. Trajectory clustering and an application to airspace monitoring. Intelligent Transportation Systems, IEEE Transactions on. 2011;12(4):1511-1524.

[10] Lee AG, Weygandt SS, Schwartz B, et al. Performance of trajectory models with wind uncertainty. AIAA Modeling and Simulation Technologies Conference; Chicago, Illinois; 2009.

[11] Zheng QM, Zhao JY. Modeling Wind Uncertainties for Stochastic Trajectory Synthesis. 11th AIAA Aviation Technology, Integration, and Operations (ATIO) Conference; 2011 Sep 20-22; Virginia Beach, VA; 2011.

[12] Lymperopoulos I, Lygeros J. Sequential Monte Carlo methods for multi-aircraft trajectory prediction in air traffic management. International Journal of Adaptive Control and Signal Processing. 2010;24(10):830-849.

[13] Hu J, Prandini M, Sastry S. Aircraft conflict prediction in the presence of a spatially correlated wind field. Intelligent Transportation Systems, IEEE Transactions on. 2005;6(3):326-340.

[14] Kandepu R, Foss B, Imsland L. Applying the unscented Kalman filter for nonlinear state estimation. Journal of Process Control. 2008;18(7):753-768. 